AfricanResearch Review vol.1(1)

\title{
Implementation Of Strategic Management: The Challenges And Implications For Organizational Change
}

\author{
Friday O.Okpara
}

\begin{abstract}
Creativity and innovation is the new game plan inherent in strategic management. Only the discerning organizations can manage the changes and vagaries through the implementation of effective strategic management. This article examines the concept of strategic management and its implication for organizational effectiveness in line with the trend of globalization.
\end{abstract}

\section{Introduction}

The world around us has transformed like never before. We are Living in very Confused time, because the forces that gave structure and shape to our lives are disappearing. It has now become a worn out cliché to talk about "change" and it's resultant effects in business organizations-"The old order changeth, yielding place to the new order." Drucker (1985), stated thus: Set aside technology, wars, politics, economics, and business for a moment. The greatest revolution taking place today is in the demographic makeup of the nations of the world. We are living in a world economy now, which is not the same as an international economy. 1t is more competitive and more dangerous. Competition can turn up overnight any place. The probability of any prediction coming true is no better than $2 \%$.

One cannot manage change. One can only be ahead of it. Everybody has accepted by now that "change is unavoidable." But this still implies that change is like "death and taxes" :It should be postponed as long as possible, and no change would be vastly preferable. Drucker (2000). But in a period of upheavals, such as the one we are living in, change is the norm. To be sure, it is painful and risky, and above all it requires a great deal of very hardwork. But unless it is seen as the task of the organization to lead change, the organization will not survive. In a period of rapid structural change, the only ones who survive are the change Leaders.

It is therefore a fundamental challenge for management that its organization become a change leader. A change leader sees change as opportunity. A change leader looks for change, knows how to find the right changes, and knows how to make them effective both within and outside the organization.

This requires:

1. Strategies to make the future.

2. Systematic methods to look for and to anticipate change.

3. The right way to introduce change, both within and outside the organization.

4. Strategies to balance change and continuity. 
It is with these four requirements as noted by Drucker (2000) for being a change leader that this paper concerns itself. The change leader puts every product, every service, every process, every market, every distribution channel, every customer and end-use,on trail for its life. And it does so on a regular schedule. The question has to be asked- and asked seriously - "If we did not do this already, would we, knowing what we now know, go into it?" if the answer is " no", the reaction must not be "Lets make another study." The reaction must be "what do we do now?" The organization is committed to change. It is committed to action through the implementation of strategic management.

Consequently, we must study change and its various manifestations to successfully deal with it and be ahead of it or else we may swept by the tidal, tectonic changes sweeping every nation, every industry and every organization. The linearity that marked the past will no longer apply to the future. Globalisation and the rise of new zones of intense economic and consumer activities will breed the need for organizations that are big enough to capitalize on different opportunities but small enough to be nimble in response to local requirements. According to Kotler, Al Ries and Trout(1999) that really translates into a multitude of new niche markets of consumers, whose behaviour is largely unknown.

Today's organizations have their tails on fire. We are now operating in a "Darwinian marketplace" where "the law of the jungle" prevails. We are into a dog-eatdog game, where the game plan is the survival of the fittest. To be relevant in tomorrow market, the management and the organization should abandon yesterday. They should immediately free resources from being committed to maintaining what no longer contributes to performance, and no longer produces results. Infact, it is not possible to create tomorrow unless one first sloughs off yesterday. To maintain yesterday is always difficult and extremely time-consuming. To maintain yesterday therefore always commits the organization's scarcest and most valuable resources- and above all, it's ablest peopleto non results. Yet to do anything different- let alone to innovate-always runs into unexpected difficulties. It therefore always demands leadership by people of high and proven ability. In addition, if these people are committed to maintaining yesterday, they are simply not available to create tomorrow.

Management must create tomorrow through strategic management to maintain the organization as a "going concern" and for continuous improvements in the operations of the organization and its relevance in the marketplace. They lead to product innovation. They lead to service innovation. They lead to new processes. They lead to new businesses. Eventually continuous improvements lead to fundamental change.

The big challenge in creating tomorrow is not predicting tomorrow. There is not a single future out there waiting to happen. The real challenge is not to predict which of those potential futures will actually materialize. Instead, the goal is to try and imagine a future that is plausible. There are some boundary conditions that management and the organization must understand, like what is going to happen to lifestyles, technology, regulation, etc. Those are the edges of the canvass, and what management paint on the canvass is a product of their own imagination. The management and the organization must harness the discontinuities- the things that are driving change. 
Today's organizations are in distress for lack of vision and knowledge. They are groaning under the weight of collection myopia. There is an acute shortage of vision and mission, intellectual vigour and critical thinking even in the multinational corporations. Strategic management is therefore required as a vital force to inject change in the organizations. It is the think tank when all other units are blind, they the ones granted to recognize the warning sign, to interpret the signs of the times, and to see the light beyond the tunnel.

\section{Strategic Management}

Strategic Management is concerned with deciding on strategy and planning how that strategy is to be put into effect. It can be thought of as having three main elements within it. There is strategic analysis, in which the strategist seek to understand the strategic position of the organization. There is a strategic choice stage which is to do with formulation of possible courses between them. There is a strategic implementation stage which is to do with planning how the choice of strategy can be put into effect.

Strategic Management is an innovative Management concept that perceives and focuses on organizational efficiency as a formal system with adequate provision for consistency, logically, preciseness, effective communication of goals and objectives, rationality and consistent flexibility towards the management of men, materials, machines, money and moment in the workplace. Plans are prepared on definite time cycle and in the context of a well structured and all embracing organizational system designed to operate in a continuum. The key element of strategic management anchors on where the organization wishes to be and how the work resources of the organization are coordinated to achieve the objectives at a particular time.

Concisely, strategic management provides solution to the following:

"Where are we?

Where do we want to be?

How do we get there?"

By so doing, the mission, vision, and objectives of the organization are redefined in accordance with the environmental factors. The reforms in the public service should be vigorously pushed with a strategic mandate and focus, strategic management can make a difference, compared with the various past reforms which monumentally failed to realize the intended desire and impact on the overall performance of the economy. In actual practice, strategic management revolves around the following separate tasks as follows:

1) Determining long term direction of the organization;

2) Assessing external environment and competitive position;

3) Establishing overall objectives, goals and strategic;

4) Determining resources requirements;

5) Establishing the foundation for tactical and operational plans and programmes.

The challenge of change - Managing it, enacting it, and leveraging it - has become one of the most important topics on today's corporate agenda in both the private and public services. The change agenda is clear - create a highly profitable, entrepreneurial 
enterprise capable of operating in the global, high-technology market place for public institutions, the market place is to create public value for the citizenry. To accomplish thus, broad-based cultural and structural changes are required based on four key dimensions:

a) A shift in the organizational culture to first nurture and later demand entrepreneurial behaviour from all employees.

b) An investment in developmental activities (focusing on both behaviours and skills) that would prepare individuals at all levels of the organization to operate in the new culture and structure.

c) New systems (Management and information) to support the transformed organization.

d) A new organizational architecture that would facilitate entrepreneurial behaviour.

Pursuing these require committed and visible leadership from the top of the organization, public institutions should reshape the organisation's top team, recruiting executives capable of role modeling the behaviour required for the new public service culture and of using and monitoring others in the use of the tools and techniques of entrepreneurship and re-engineering. The public service requires the pro-active support of the entire workforce with a rekindled motivation. The management is required to lead the transformation in partnership with the new stakeholders. This team is to lead the organization to its new objectives, mission, and vision through a radical and aggressive result oriented strategic management.

The diagram below is a simplified operational model of strategic management, which highlights the key issues involved without the complexity that often accompanies such discussion. The diagram separates strategy from goals objectives, i.e. it implies that strategy is a means to an end and should be separate from the defining of ends. The diagram also highlights that there is more than one kind of strategic planning, i.e. at corporate (while corporation wide) level and at a separate business level (e.g. as for subsidiary companies or divisions).

It suggests that goals/objectives are not only set for long term, ie a proactive process of deciding where you want to be in a given time, but also may be developed in the shorter-term in response to changes in the operating environment, i.e. where part of strategic thinking is to be able to react at a reasonable early stage to head off unexpected changes in business conditions 


\section{Key Issues in Strategic Management}

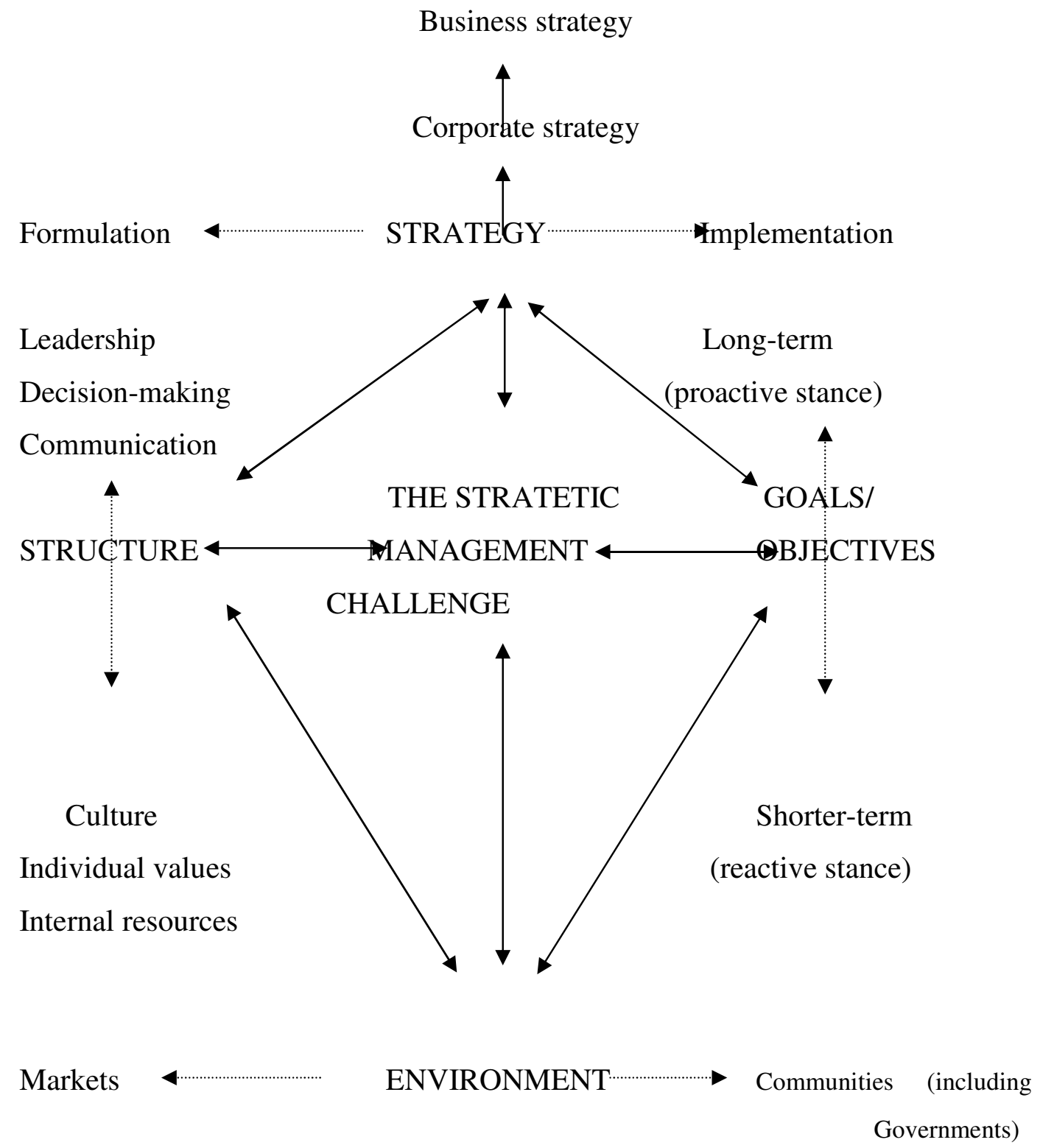

Fig. 1 Key issues in strategic management adopted from Cole (1997)

A key aspect of strategic management is the development of a viable structure of leadership and decision making to promote and sustain the implementation of strategy, this structure implies the application of values through the organization's own value system (culture) and those of individuals; it also implies the organization of the necessary physical and human resources to achieve the goals and objectives set down in the strategic plan. 
The diagram also indicates that the external environment is not only composed of markets (ie potential/actual purchasers of the organisation's goods or services) but also of communities of people (including governments) who have needs and priorities which are of a non-market nature, and who may have power to force change on the organization.

Finally, the diagram suggests that the role or challenge, of strategic management is to orchestrate all these diverse elements into an overall plan for the success of the enterprise.

Strategic Management therefore is a "systematic approach for managing change which consists of:

1) Positioning of the firm through strategy and capability planning;

2) Real-time strategic response

3) Systematic Management of resistance during strategic implementation" Ansoff (1984).

\section{Organisational Change}

Change is a process. Change in an organization can influence, and be influenced by, several important features of organizational life - the organizational mission and strategy, its structure, products and processes, its people and culture, and the nature of the technology employed. These features of the organization are themselves affected by the nature of internal and external environment.

The internal environments are triggered by the following factors as noted by Cole (1999).

- planned changes in strategy as a result of revised mission or goals (themselves largely influenced by external considerations)

- efforts to introduce cultural changes (e.g. in management style, collaborative working etc)

- need to improve productive efficiency/make better use of resources

- $\quad$ need to improve the quality of products of services

- need to respond to the development of potential new products/services devised by $\mathrm{R} \& \mathrm{D}$ or marketing departments

- $\quad$ need to improve standards/systems for dealing with suppliers

- need to deploy people (the human resources) where they are most effective.

The external environment may be trigged by the following factors.

- Changes in demand for the organisation's products or services (e.g. as a result of changing consumer preferences, action by competitors, government etc)

- Threatening tactics of competitors (e.g. by aggressively cutting prices or producing an advantageous enhancement to a product or service)

- Arrival of a new comer with a competing product or service

- Takeover of the business by a more powerful enterprise

- Merger of the business with another

- Failure of a key supplier to meet the organisation's requirements 
- Changes in the terms of trade (e.g. currency exchange rates, tariffs etc)

- Inability to attract sufficient numbers of skilled employees

- Development of new technologies now available for application

- Political changes (eg new labour laws, changes in company law, taxation etc).

Organisational change is not a car wash, it comes with resistance. It is therefore, vital that managers planning changes should acknowledge that some resistance within and without the organization will be unavoidable. Management at every level in the organization are potentially liable to feel threatened by change, and thus change must be "well packaged and sold" to those affected by it. The agents of change must therefore be prepared to proactively manage change in the organization.

Consequently, in dealing with issues of resistance to change and overcoming inertia. Kanter (1984) suggested a number of possible actions.

- As a prerequisite to change, top management must be personally committed to supporting innovation and must learn to think integratively.

- A "culture of pride" should be encouraged within the organization, in which achievements are highlighted and where experienced innovators serve as consultants to other parts of the organization.

- Access to power sources (Management Committees etc) should be enlarged to improve support for innovatory experimental proposals.

- Lateral communication should be improved. Cross-functional links should be developed, and staff mobility should be encouraged.

- Unnecessary layers of hierarchy should be reduced (ie a flatter structure should be aimed for) and authority should be pushed downwards ("empowerment" of staff).

- Information about company plans should be more widespread and given as early as possible to enable people to contribute to change before decisions are made (eg by means of taskforces, problem-solving groups etc).

Peters propositions, have notable changes in the management of organization:

1. Decentralization is likely to increase

2. Decision-making is likely to be diffused throughout the organization (i.e. empowerment practice will increase)

3. Stability will be maintained chiefly through vision and values (i.e. company culture)

4. Innovation will be encouraged, but in manageable amounts, on a more or less continuous basis.

5. Mistakes will be dealt with as positive forms of learning

6. Corporate decisions and strategies will be directed fundamentally at serving the customer.

7. This sense of the customer will be employed within organizations (i.e. where each employee is seen as the customer of another)

8. Whilst mistakes and failures will be accepted as part of the drive towards excellence, the emphasis on total quality will be stronger as the organization strives to "get it right first time and every time" 
9. The overall impact on organization structures will be a move away from mechanistic forms in favour of organic structures.

\section{Formulating a Strategy}

The Corporate objectives are established at the top management level (strategic management level), corporate planning, leading to the formulation of corporate strategy, is the process of:

(a) deciding on the organisation's objectives and goals, including the determination of which and how many lines of business to engage in, like the Ethiopian Electricity Corporation or the Power Holding Company of Nigeria is in the business of generation, transmission and distribution of electricity as well as into the marketing of the product - electricity.

(b) acquiring the resources needed to attain those objectives, and

c) allocating resources among the different businesses so that the objectives are achieved.

Business planning, leading to the formulation of business strategy, is the process of determining the scope of division activities that will satisfy a broad consumer need, of deciding on the divisional objectives in its defined area of operations, and of establishing the policies adopted to attain those objectives. Strategy formulation involves selecting division goals and objectives and establishing the mission of the business, after delineating the scope of its operations vis-à-vis markets, geographical areas, and/or technology.

In functional planning, the departments develop a set of feasible action programmes to implement division strategy, while the division selects - in the light of its objectives the subsets of programmes to be executed and coordinates the action programmes of the functional departments. Strategy formulation involves selecting goals and objectives for each functional area (marketing, production, finance, personnel, research, and development etc) and determining the nature and sequence of actions to be taken by each area to achieve its objectives.

The process of strategy formulation can be thought of as taking place at the three managerial levels. Hence the effectiveness of Corporate Strategy is usually enhanced by the strategic plans - by formal process of setting objectives and deciding on action plans to achieve them. It is the environment that provides the framework to conceptualize strategic planning within the organization. The following elements are crucial to the process:

- The definition of the philosophy of the organization i.e. why does it exist? What are its contributions to society?

- What is the mission of the organization?

- What are the strengths and weaknesses of the organization? What opportunities and threats are perceived in that environment? What factors enhance or inhibit the achievement of any future causes of action to be undertaken by the organization?

- What is the current organizational structure? 
How adequate is it with reference to the environment and strategic responses.

The process of strategy formulation then involves the following steps:

1. Scan status

2. Generate goals and objectives

3. Define problems

4. Design alternatives

5. Predict Consequences

6. Evaluate alternatives

7. Review plans

8. Select strategy

9. Implement strategy

10. Evaluate strategy

For example to formulate a Strategic Human Resource (Manpower) plan, an organization must do the following:

- Determine human resources implications of business strategies by looking at external and internal constraints

- Confirm their implications for human resources activities i.e. selection, compensation, personnel development etc

- A specification of the kinds and numbers of individuals the organization will need to meet its marketing innovation, productivity, profitability and service objectives.

- Forecast from current personnel inventories of how will its current state meet projected needs and recheck with forecasted supplies from external labour market.

- Formulate plans for recruitment, selection, placement and development of human resources.

All of these are necessary to ensure that the organization has the right number of people, possessing the right types of skills at the right times, in the right jobs and at the right places. Generally, five steps are involved in developing a Human Resources Information System:

i. System planning

ii. System design and development

iii. System implementation

iv. System evaluation

v. Human resource inventory

Then, a forecast of human resources by considering the supply and demand from internal and external sources is undertaken. Consideration is given to quantitative, qualitative, temporal, locational and job positioning factors; often ratios and economic models are used here.

The organization undertakes succession planning i.e. set plan horizon and identifying replacement candidates for giving positions, accessing current performance and readiness 
for promotion synchronizing individual career goals with organization goals and objectives.

Finally, action plan is undertaken in the areas of organizational entry, employee development, compensation and utilization. However, throughout the process, the following must be addressed to ensure that current human resources are optimally utilized.

a) that task performance must manifestly be related to the goals and objectives of the organization is considered with the issue of effectiveness.

b) That the majority of work time is devoted to goal related tasks, tasks that result in outputs or results - concerned with both effectiveness and efficiency.

c) That the majority of an employee's work time spent performing at the individual's highest knowledge/skill level - primarily involves efficiency.

d) That the majority of employees are responding to a climate that encourages the expenditure of a high degree of effort is concerned with effectiveness.

e) That workflow is structured to minimize slack and duplication of effort - is concerned with efficiency, more so than any of the other conditions.

f) That structure and technology are integrated in such a fashion as to improve task performance - deal with overall organizational effectiveness.

\section{Implementing Strategic Management}

Bryson (1995) outlined ten logical steps to start a strategic management process in an aggressive organization that strive to remain relevant in the market place. The steps are highlighted thus:

\section{1) Initiative and Agree upon a strategic-planning process}

The purpose of the first step is to negotiate agreement among key internal (and perhaps external) decision makers or opinion leaders about the overall strategic planning effort and the key planning steps.

2) Identify Organizational Mandates

The formal and informal mandates placed on an organization consist of the various "musts" that it confronts. Bryson notes that it is surprising how few organizations know precisely what they are (and are not) formally mandated to do.

3) Clarify Organizational Mission and Values

An organization's mission, in tandem with its mandates, provides its raison d'etre, the social justification for its existence. For a government agency or non-profit organization, this means there must be identifiable social or political needs that the organization seeks to fill. Viewed in this light, organizations must always be seen as a means to an end, not as an end in themselves.

4) Assess the Organization's External and Internal Environment to identify strengths, weaknesses, opportunities, and threats

The planning team should explore the environment outside the organization to identify both opportunities and threats. It should explore the environment inside the organization to identify both strengths and weaknesses.

5) Identify the Strategic Issues Facing the Organization 
Together, the first four elements of the strategic planning process lead to the fifth, the identification of strategic issues. Strategic issues are fundamental policy questions or critical challenges that affect an organization's mandates, mission, and values; product or service level and mix; clients, users, or payers, or cost, financing, organization, or management

6) Formulate Strategies to manage their Issues

A strategy is defined as a pattern of purposes, policies, programs, actions, decisions, or resource allocations that define what an organization is, what it does and why it does it. Strategies can vary by level, by function, and by time frame. Strategies are developed to deal with the issues identified in the previous step.

7) Review and Adopt the Strategic Plan or Plans

Once strategies have been formulated, the planning team may need to obtain official approval to adopt them and proceed with their implementation

8) Establish an effective Organization Vision

In this step, the organization develops a description of what it should look like once it has successfully implemented its strategies and achieved its full potential. This description is the organization's "vision of success". Few organizations have such a description, yet the importance of developing one has long been recognized by wellmanaged companies, organizational psychologists, and management theorists.

9) Develop an Effective Implementation process

Just creating a strategic plan is not enough. The changes indicated by the adopted strategies must be incorporated throughout the system for them to be brought to life and for real value to be created for the organization and its stakeholders.

10) Reassess Strategies and the Strategic Planning Process

Once the implementation process has been under way for some time, it is important to review the strategies and the strategic management process as a prelude to a new round of strategic management. Much of the work of this phase may occur as part of the ongoing implementation process.

\section{The Problems of Implementing Strategic Management}

In spite of the exposure on the virtues of strategic management, it has become clear that most organizations suffer economic setbacks due to problems internal rather than external to them. One of these problems which is almost endemic is that of introducing, developing and implementing strategic management. Some of the problems include the following:

In the first place, there is suspicion and fear by managers that strategic management might expose their weaknesses as a result they refuse to cooperate by withholding vital planning information. This conservative attitude and resistance to change exacerbates the already difficult task of planning managers.

The intra-organizational politics in the workplace, particularly common in business organizations, is another problem. They tend to be strifes within various sections of an organization, and in such a situation of organizational politics, the planner must be seen to be neutral, for if he/she is identified with a group, he/she may be creating antagonism in other areas, and that will naturally make his/her job very difficult when navigating through the organization in the humble discharge of his/her duties. 
Non-availability of reliable statistical information from both within the company or from elsewhere frustrates planning efforts. As well as inconsistency in government policies as government, policies are consistently inconsistency in developing countries.

The poor management of the political economy especially in developing countries, seems to deal with its various economic crises through short-term measures, as can be seen in the recent economic reforms. This often occur without adequate warning to the organizations. This creates problems of planning. Most organizations see such economic measures as a threat; rather than an opportunity for improving corporate performance through a change in strategy.

Finally, the poor state of social infrastructure and political instability is another problem to the organizations strategic management. In most cases, they are quickly rendered obsolete and force the organizations to get back to the drawing board with high losses and risks.

\section{The Benefits of Strategic Management}

Bryson (1995) outlines four benefits of strategic (planning) Management in his book "Strategic Planning for Public and Non profit Organisation: A Guide to Strengthening and Sustaining Organisational Achievement". These benefits are:

i. Promotion of strategic thought and action.

ii. Improved decision making

iii. Enhanced organizational responsiveness and improved performance - flows from the first two.

iv. Benefits the organisation's people.

These is no more important element in performance based Management than Strategic plans. These plans set the organisation's course, its overall programmatic and policy goals, and describe how these goals will be achieved. However, Bryson (1995) cautions Managers to use care in "How they engage in Strategic Management because their success will depend at least in part on how they tailor the process to their specific situation". Eadie (1996) concurs with Bryson. He scribed the following: "....the Practitioner should always keep in mind that most golden of maxims: tailor the application to their own organization, with its own unique conditions and needs".

In a guide provided to heads of executive departments from the office of Management and Budget, the contents required by the Government Performance and Results Act are:

- A comprehensive mission statement covering the major functions and operations of the organization,

- General goals and objectives, including outcome-related goals and objectives, for the major functions and operations of the organization.

- A description of how the goals and objectives are to be achieved, including a description of the operational processes, skills and technology, and human, capital, information, and other resources required to meet those goals and objectives. 
- A description of how the performance goals included in the plan required are related to the general goals and objectives in the strategic plan

- An identification of those key factors external to the organization and beyond its control that could significantly affect the achievement of the general goals objectives; and

- A description of the programme evaluations used in establishing or revising general goals and objectives, with a schedule for future programme evaluations.

Bryson (1995) however, warned that strategic planning is no panacea. He stated that “...governmental strategic planning is probably most needed where it is least likely to work. Governmental Strategic Planning would appear to work best in units that have effective policy - making boards, strong and supportive process sponsors, superb process champions, good strategic planning teams, enough slack to handle potentially disruptive crises, experience in coping with major disruptions, and a desire to address what is truly important for the organization". He added, "Any unit with those features probably already uses some sort of 'Strategic thinking and acting' process."

Bryson (1995) further submitted that there are two compelling reasons for some organizations to hold off on a formal strategic planning effort. First, strategic planning may not be the best first step for an organization whose roof has fallen. For example, an organization may need to remedy a cash flow problem before undertaking strategic planning. Or it may need to postpone strategic planning until its fills a key leadership position. Second, if an organization lacks the skills, resources, or commitment by key decision makers to produce a good plan, strategic planning will be a waste of time. He added, "Strategic planning will be a waste of time. He added, "Strategic Planning also probably should not be undertaken if implementation is extremely unlikely".

\section{Conclusion and Recommendations}

In the light of the above, it will be true to state that no business organization may succeed in improving on its performance without strategic management. In the long run, no organization may indeed, survive in today's highly volatile and competitive dynamic business environment, therefore strategic management assumes added important as it embraces organizational change.

It must be noted that the prosperous day of limited entry, courteous competition, and statutory protection are over. Business organizations that are not accustomed to the risks and rewards they are facing today are not likely to see tomorrow. Unfortunately ,many are not equipped for the intensity and diversity of the new competition brought about by dynamics in the market place. Instead, the rewards of success will go to those organizations that can manage the complexities of the proactive market players, cope with the dynamic environmental forces, and deal with global and local competition through flexible strategic management.

The contention of this paper, therefore, is that strategic management constructed with redefined vision and mission, is an essential drive and indeed, an imperative to survival in the marketplace. The competition is expected to get tougher in a deregulated globalised market, only the best and the fittest will survive. The organizations are 
expected to be proactive in their commitment to a market driven strategic management. The task is simple to state, but difficult to execute. The organizations have to press harder by redesigning their strategies as well as redefining their mission in accordance with the changes in the marketplace. This means, using their best insights and instincts about trends in the marketplace to formulate action plans through product innovation in design and delivery of products and services. They are expected to go into the marketplace, stay in close contact with the customers and non-customers, competitors and technology in one's own industry and others; about international finance and about the changing global economy. For that is where the results are. Inside the organization there are only cost centres. The only profit and investment centres are the customers whose cheques have not bounced.

\section{References}

Hussey D. (1998) Strategic Management from Theory to Implementation. New Delhi. Buterworth Heinemann.

Adewunmi (1995) "Strategic Planning in Commercial Banks: Framework for the design of a Management Information System". The CBN Bullion, Silver Jubilee Edition Vol. 2.

Drucker P. F. (1974) Management: Tasks, Responsibilities,and Practice: London: Letts Educational.

Drucker P. F. (2002) Management Challenges for the $21^{\text {st }}$ Century. London: Butter Worth/Heinemann.

Thompson J. L.(2001) Strategic Management. Canada: Gray Plublishing, Tunbridge Wells.

Sinha D. and Kasande S. (1999) Business Policy and Strategic Management. Mumbai: Nirali Prakashan.

Okpara F. O. (2001) "Strategic Management and Change in the Telecommunications Industry: Implications for the Leadership Position of NITEL". Being a paper presented at a Workshop Organized by IIT Consulting Held at the Conference Hall of Benue Hotel, Makurdi - Benue State - Nigeria.

Hammer M and Champy J. (1994) Re-engineering the Corporation: A Manifesto for Business Revolution. London: Nicholas Brealey publishing.

Champy J. (1995) Re-engineering Management: The Mandate for New Leadership New York: Harper Business.

Cole G.A. (1997) Strategic Management. London: Letts Educatioal

Cole G.A. (1999) Management Theory and Practice. London: Letts Educational.

Steiner G.A. (1984) Strategic Planning: What Every Managers should know. 
Bryson (1995) Strategic Planning for Public and Nonprofit Organizations: A Guide to Strengthening and Sustaining Organizational Achievement.

Talwar, R. (1994) Re-engineering - A wonder Drug for the 90's? in coulson - Thomas (Ed), Business Process Re-engineering - Myth or reality, Kogan page.

Peters, T. and Waterman, R. (1982) In search of Excellence: Lessons from America's Best-Run Companies, New York: Harper and Row.

Peters, T. (1988) Thriving on Chaos -Handbook for a Management Revolution. New York. Macmillan. 